\title{
Two empirical research projects into the impact of teaching the concept of drivers to preschool children in Italy
}

\author{
(C) 2015 Cesare Fregola
}

\begin{abstract}
Fourth-year student teachers on a degree course at Roma Tre University were supervised as they conducted empirical research to introduce transactional analysis to primary schoolchildren, with the aim of developing their own self-efficacy and autonomy whilst demonstrating that the teaching of drivers (Kahler 1975) to children led to progressive development for those children of the metacognitive capabilities and self-awareness needed to make their own decisions about behavioural choices. The limitations of small sample groups are acknowledged as is the fact that the supervision came from authors whose previous work had provided the basis for the questionnaires designed and used by the students.
\end{abstract}

\section{Key Words}

transactional analysis, drivers, student teachers, primary schoolchildren, self-efficacy, educational psychology

\section{Introduction}

For many years the author and Daniela OImetti Peja (1998) collaborated to research the integration of transactional analysis and the self-efficacy model (Olmetti Peja 1998, Fregola \& Olmetti Peja 2007) in an effort to identify synergies between educational transactional analysis, educational science, educational psychology, and the specific requirements that define the competencies of teachers. Our research has taken place with those training to teach at Nursery and Primary schools, whilst they were students of a degree in Sciences of Primary Education at the University of Roma Tre.

Previously reported research has concerned the role of drivers (Kahler 1975) within the teaching and learning processes of mathematical calculations (Fregola 2010), and the relationship between learning and the social, cultural, financial and political contexts in which we live (Fregola \& lozzelli 2013). The 'drivers' research has since been extended to the learning of history, foreign languages, and Italian grammar.

Here I report on two small research projects concerning investigations into drivers in primary school children. The paper begins with a general theoretical introduction, followed by separate project reports, and concludes with general comments on limitations and conclusions.

\section{Philosophical Background}

Our researches focus on educational theory and practice and are expressions of a methodology involving the creation of environments that encourage and facilitate connections, links between abstract and concrete, and theories and practices that can improve the efficiency of the teaching and learning processes within a complexity paradigm of a learning society (Fregola 2010). We wish to challenge the notion that synergy and integration between the disciplines involved in the learning processes are not connected to the internal world. Educational methodologies appear to support out of date psychological and pedagogical research, such that there has been a considerable delay in incorporating more recent developments in the areas of educational psychology (Hill, 2000), experimental pedagogy (De Landsheere, 1976), the diffusion of the didactic technologies (Maragliano, 2007) and virtual technologies (Levy, 1997).

The reform of primary education in Italy in 1985 delineated a change in the teaching intentionality and practice but the cultural matrix of the learning is still based on cognitive and behavioural models that see the mind as a black box, and as something that cannot be measured behaviourally, directly or indirectly (Boscolo, 1997). We believe that there 
may be some political reasons that go back to the censure of psychology operated by Fascism, and that the reforms of the school of Gentile and Giuseppe Lombardo Radice (Marrone, 2012) have promoted a pedagogy that reinforces the ideology and educational opinions of that historical time. The subsequent reforms changed the contents, the methodologies and the school organisation but there was no attention to the epistemologies or to real integration between basic knowledge, specific knowledge, learning outcomes, teaching processes and development of individual talents.

Within this ongoing debate, we are interested in a didactic that involves the creation of environments that harness learning processes and relational interactions to facilitate specific teaching. The students internal world can be accessed by teachers' behaviours that are part of traditional educational practice (Ballanti, 1979) if combined with those of educational transactional analysis. The first results supported the research in this area and confirmed the already established theories and competencies of TA previously applied in the educational field (Chalvin, 1986). In particular, we refer to the development of self-awareness for the teacher, educator or trainer, and those psychological phenomena described as ego states and drivers.

The results show increased self-awareness, understanding of and recognition of other processes related to learning and educational decisions, and in turn help educators to identify, analyse and operate in the interaction with confidence due to better understanding the structures that organise thoughts, feelings and behaviours and are observable in the relational context. This allows influencing of the learning process in those aspects that are dependent on internal factors, within the boundaries of the role. Educators can, therefore, utilise the structures to deliver more potent teachings supported by competent affective modalities.

\section{Theoretical Background}

Gagné (1973) indicated that people make choices of experiences that allow them to feel self-efficient, and choices of environments that challenge their abilities and stimulate the development of competence. He defined a concept of strategy, different from problemsolving, and central to the individual's competence, seen as a series of procedures that self-generate and are specific for each individual. These procedures are not all transmissible so the student and/or teacher need to mediate, support and provide feedback in order that self efficacy can lead to shifts in cognitive, metacognitive and affective variables.
Bloom (1974) introduced the concept of the 'academic learning self', defined by the 'index of perception' that the student has of themself, influenced by the number of years over which the student was evaluated. The affective attitude towards the specific learning material influences a series of learning tasks, linked with the perception that the student has of them. The affective disposition towards school is also generalised to the relationship with parents, teachers and peers. Bloom proposes, therefore, that a certain amount of success and approval, and failure and disapproval, determined by the evaluation of the learning outcomes, brings the student to a formulation or generalisation of their own ability to learn. He regards the learning outcomes as independent of the characteristics that students have at the point of entry, and associates them to cognitive behaviours and affective traits that relate to the communicative interaction and the way the teacher structures the task environment. This means that the total of the procedures, sequences of instructions, setting up of the space, materials and didactic tools have to be adapted to the characteristics of the students at the entry point and are therefore a macro variable defined as 'quality of instruction'.

When combined with transactional analysis, Bloom's model of the quality of instruction can be amended as shown in Figure 1. The addition of the TA concepts allows the teacher to observe variables relative to cognitive behaviours and affective traits in relation to the prerequisites of the specific learning task, allowing the teacher to plan interventions using strategies most suitable for operating a sort of decontamination of the 'Educational Parent' with the 'Educational Adult'. This does of course require that the teacher accepts that affective traits relative to the attitudes of students are changeable.

Bronfenbrenner (1979) provided a central model of developmental psychology with an ecological perspective. The focus of this model of pedagogical discourse allows us to consider the evolutionary dynamics of the social contexts and relationships in which the action takes place, hence taking into account the processes of continuous innovation that characterise the social and cultural environment in which the child is immersed. Cornoldi \& De Beni (1991) conducted research on metacognition and its relationship with learning and its processes. This model enables teachers to develop the observational capacities of regulatory factors of cognitive processes involved in learning, and hence becomes the basis for the development of the skills of monitoring their self-efficacy in the management of 


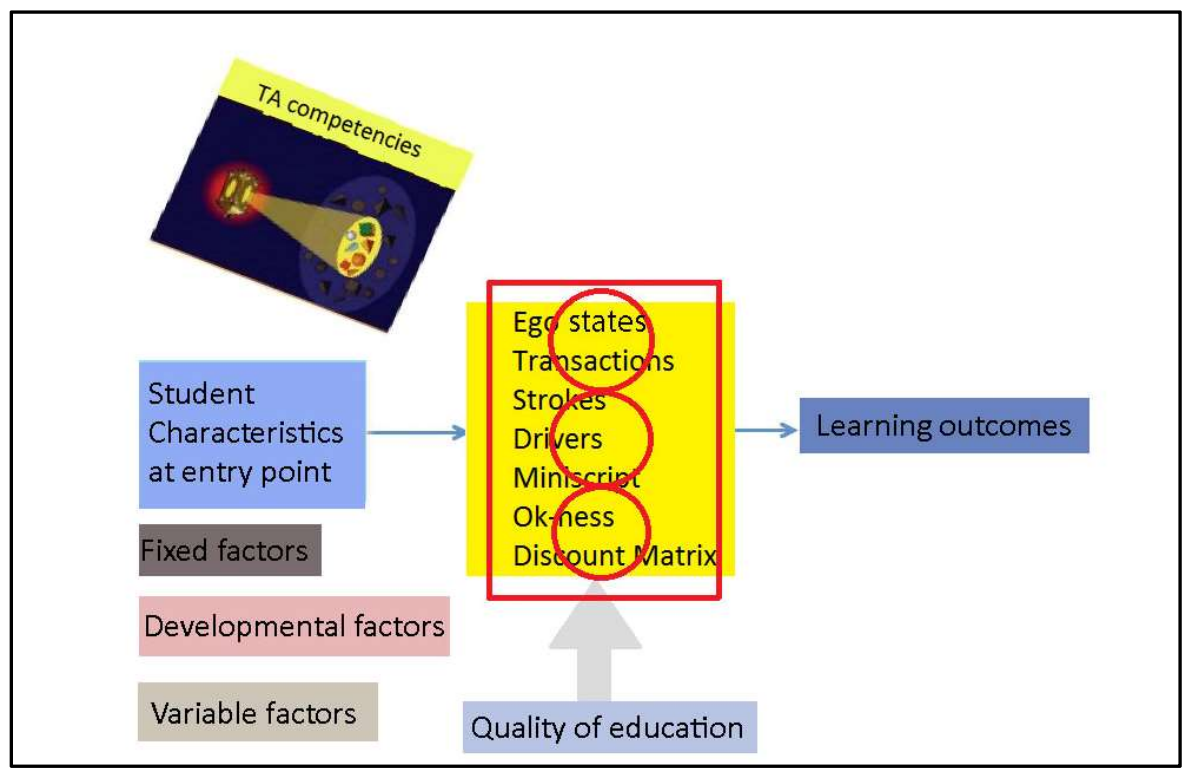

Figure 1: An Integrated Model

the processes of teaching and learning. Hill (2000) developed a survey on learning theories and his work is valuable because it allows us to understand the thinking of the leading psychologists of learning and schools. This is the text from which our students relate the fruits of the various theories for the process of decision teaching.

\section{Hypothesis}

From the research previously undertaken, the hypothesis emerged that affective variables can be considered resources in the same way as metacognitive variables. Being aware of the variability of these factors, we can update the methodologies using creative options that will allow a better self-expression within the learning process, and at all ages, as described as 'lifelong learning' (Alberici, 1999). This can be linked to the TA concepts of script and autonomy, in line with Berne's (1964) definition of the latter as self-awareness, spontaneity and intimacy. The script, as we know, is of central importance because it is connected to the philosophy of humanistic psychology and implies that individual talents cannot develop fully if the individual is partly blocked by distorted beliefs about self, others and the world. These beliefs were decided and are held not fully in awareness; they influence thinking, feeling and behaving in the here-and-now. In this sense, autonomy is the process that allows us to recuperate ways of communicating that move away from the script-based interactions, which are unconscious, and go towards a process of communicating within the self and with others guided by an integrating Adult.

Fregola $(1982,1989)$ previously presented an educational model aimed at improving the social and didactic communication within the learning process. At that time, the model integrated relational, cognitive, metacognitive, social and sensorimotor aspects but did not include affective factors because Fregola believed at that time that these were unchangeable. With an updated version of that model, the researchers structured learning environments of the following studies to take into account stimulus, recognition and structure hungers (Berne 1964) as the basis of the educational interaction.

\section{Ethics}

The University of Roma Tre has agreements with the Comprehensive Institute for the operation of training placements of graduating students in Primary Education, under which arrangements regular research is conducted. Each project was initially shared with faculty and then with families at a meeting of parents. Later each was presented to the children in the classroom with the help of a teacher. There is no option for the children to withdraw from the study because the lessons that form the training placements are part of the normal school schedule. 


\section{Research Project A: Drivers in Primary School Children \\ Objectives}

This project aimed at critically evaluating the acquisition of affective competencies within the development of social and personal identities of the children. These competencies may play a role in the self-regulation of the dysfunctional manifestations induced by drivers. The project also focused on those factors that activate and support driver mechanisms out of awareness. In addition to validating the questionnaire, the specific objectives for the children were:

- to become aware of their own drivers and the impact of these in the educational context

- to become aware of their own responses to the drivers of the children

- to be able to recognise the characteristics of the five drivers

- to understand the functional and dysfunctional aspects of the five drivers

- to have initiated various options of responses from each driver

Participants

The project was conducted by Alessandro Alaimo, who had attended an internationally-recognised short introductory course on transactional analysis and was in the $4^{\text {th }}$ year of a Bachelor of Science degree in Primary Teaching; he was supervised throughout the project by the author and Professor Olmetti Peja.

The sample included 25 children of 4 to 5 years of age. Of the 4-year-olds, three were girls and four were boys; of the five-year-olds, nine were girls and eight were boys. Data for another four-year-old girl is not included because she was not present for every part of the project.

\section{Questionnaire}

Alessandro Alaimo and Luca Dionisi (see Project B) developed a driver questionnaire of 25 items, which was administered at the beginning and end of the intervention. Developed under the supervision of the author and Professor Olmetti Peja, the questionnaire was designed specifically for primary schoolchildren, taking into account age and linguistic competence. Questions were simple and much attention went into the visual presentation. Short video clips were shown to the children, after which a question was read to them and the child chose an answer from amongst a range of pictures.
In addition to the questionnaire, Alaimo conducted 20 hours of observation of the children, in the form of Corsaro (1985) field notes for ethnographic observations. These were particularly aimed at observing the children's transactions which highlighted specific emotional responses. A checklist based on the material of Moiso \& Novellino (1982) was used to interpret the observations.

The observations were used to create initial profiles of the children's emotional responses, at the start and end of the intervention, which were then compared with the profile emerging from the questionnaire results. These comparisons were taken as evidence of the reliability and validity of the questionnaire.

\section{Educational Intervention}

The children in the group led by Alaimo were provided with 40 hours of educational intervention. They were invited to undertake a series of tasks: identifying the drivers of characters in a fairy-tale; creating bedrooms for the five characters; completing an exercise involving permissions that challenge the driver; and creating strategies to solve problems faced by the five characters.

When the children were told the fairy tale with the five characters, each of whose nature had typical characteristics of one of the five drivers, they were able to recognise the functional and dysfunctional aspects of the drivers and how such behaviours would impact on the well-being of the individual and the group. The children were able to experiment with changing their responses in order to find healthier alternatives.

The children were next invited to create bedrooms for each of the characters, for which they were provided with some criteria such as perfectly tidy for $\mathrm{Be}$ Perfect, unadorned for Be Strong, untidy for Hurry Up. Figure 2 shows photographs of examples of some of the bedrooms created by the children.

As a final activity the children were asked, individually, to describe a possible personal solution to a conflict between several protagonists. Then all they had to work together in identifying an action plan that took into account the cooperation of all five characters, and that would lead to success and an end of the story that incorporated the defeat of the antagonist. The sequence, therefore was: a request for individual solutions; then a request for collective solutions; followed by dialogue with the teacher to reinforce awareness of the need for a strategy that involved the action of all the characters and identification of the positive aspects of drivers. 
Responses included that the Be Perfect must complete a perfect picture; the Be Strong builds a fence to prevent access to the tree; the Try Hard builds a labyrinth to disorientate the villain; the Hurry Up puts up confusing road signs; and the Please Others asks others to negotiate with the villain.

\section{Results}

Figure 3 shows the driver questionnaire entry and exit level scores for the children, for the whole sample, the five-year-olds and the four-year-olds respectively. Try Hard, Hurry Up and Please Others have decreased, Be Perfect has increased by two points, and Be Strong is unchanged. However, these mask the changes for the different ages. No scores remained stable for the five-year-olds. Figure 4 illustrates how the results were calculated for each child.

Although based on a small sample, the results suggest a progressive development of the ability of the children to make their own decisions about behavioural choices, whether expressed directly or through fictional characters and situations. It seems that educational projects using TA concepts for primary schoolchildren can lead to a strengthening of the metacognitive capacities and affective selfawareness.
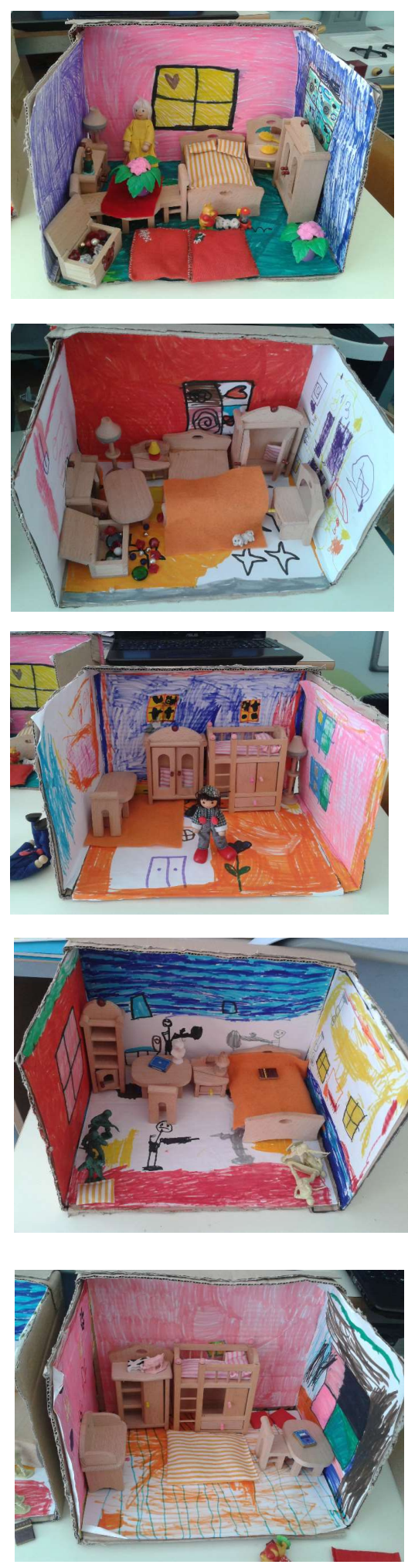

Figure 2: Examples of bedrooms created by children 

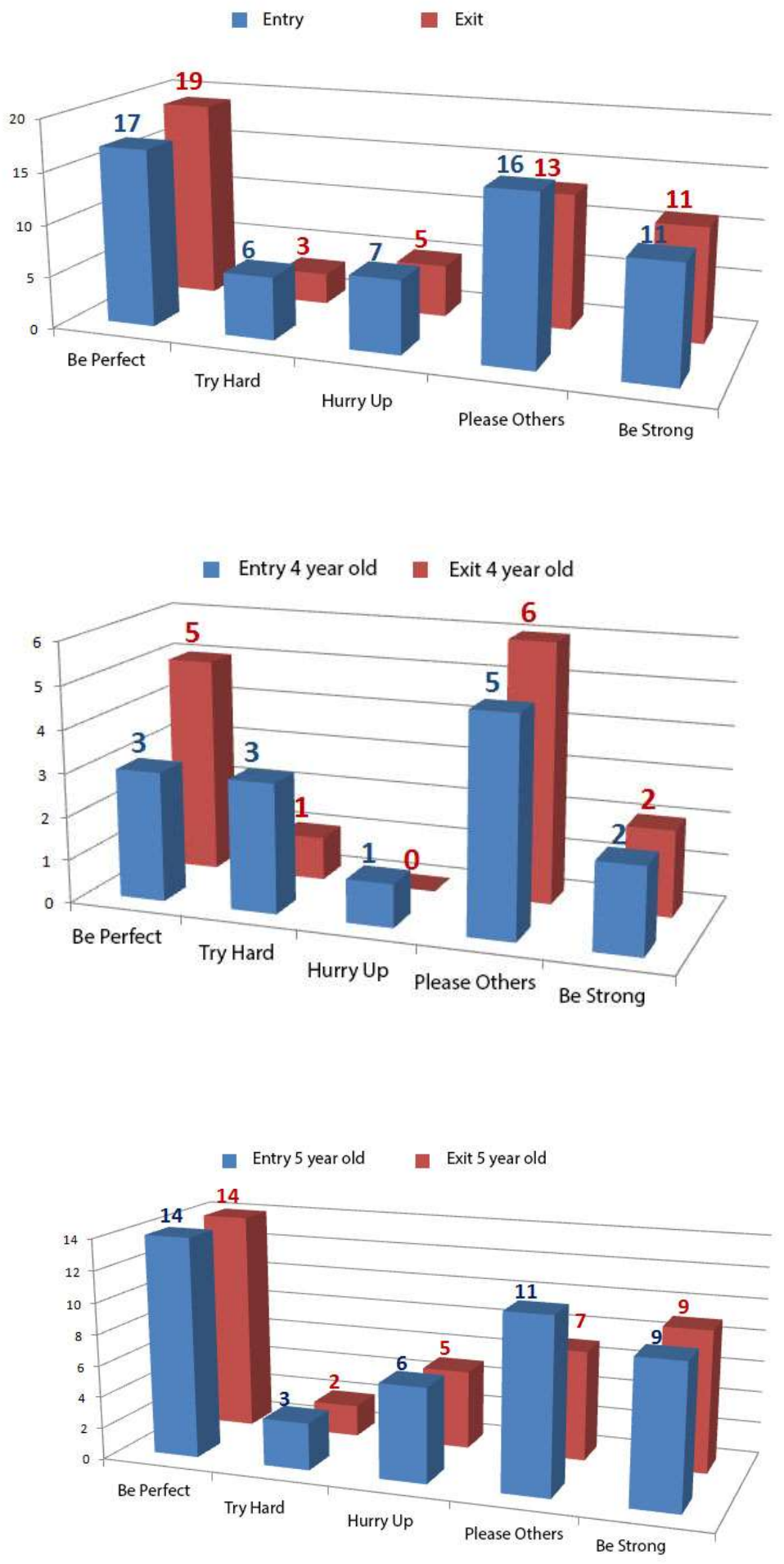

Figure 3: Driver Questionnaire Entry and Exit Level Scores 

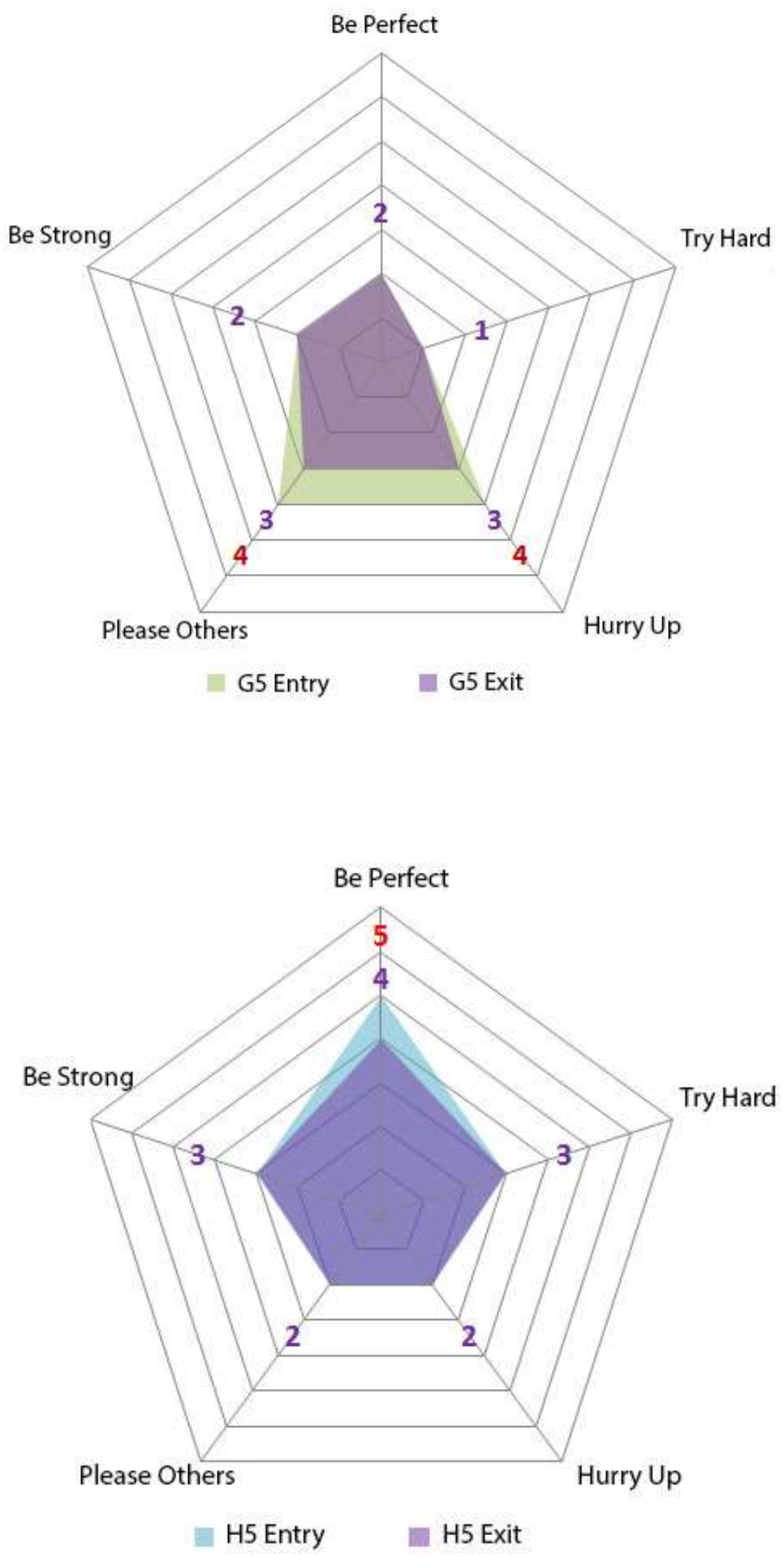

Figure 4: Examples of how resuts were calculated for each child 


\section{Research Project B: Drivers in Primary School Children \\ Objectives}

This project was aimed at helping the children to acquire and develop affective competencies and to foster assertiveness in relationship with others. In addition to validating the questionnaire, the specific objectives for the children were:

- to become aware of their own drivers and the impact of these in the educational context

- to become aware of their own responses to the drivers of the children

- to recognise their own drivers

- to apply emotional literacy in the context of play and fantasy in order to encourage the ability to reflect, within the limits imposed by the developmental age and the educational setting

Participants

This project was conducted by Luca Dionisi, who had attended an internationally-recognised short introductory course on transactional analysis and was in the $4^{\text {th }}$ year of a Bachelor of Science degree in Kindergarten education; he was supervised throughout the project by the author and Professor Olmetti Peja.

The sample for this project included 26 preschool children aged five; 13 were boys and 13 were girls.

\section{Questionnaire}

As described for Project $A$, a driver questionnaire of 25 items, developed by Dionisi and Alaimo, was administered at the beginning and end of the intervention, using the same method as described above.
Educational Intervention

60 hours of educational intervention were provided, structured into three units:

Unit 1 - five characters from five different planets are going on a rocket bus to the intergalactic Olympics. The children were involved in creating the story and performing it, which meant grasping the characters and understanding the features of each driver.

Unit 2 - five characters are kidnapped by a sixth character so that the children experience the discounting internal messages of the drivers when this happens, through engaging in individual activities for each driver and evaluating typical driver behaviours.

Unit 3 - the five characters team up to defeat the sixth character, as the children experience the verbal permissions related to each driver and engage in group activities.

The simple explicative pictures shown in Figure 5 were provided to present the characters to the children, who were then divided into groups and invited to produce intergalactic maps as shown in Figure 6, after which they also produced the passports shown as Figure 7.

\section{Results}

By the end of the project, each behavioural profile had changed, as shown in Figures 8 and 9. In half of the cases, the changes were away from peak values, in many cases appropriately. As for Project $A$, although this is a small sample size and the changes to scores could be due to chance, the results do seem to indicate that the children acquired stronger metacognitive capacities and more effective self-awareness.
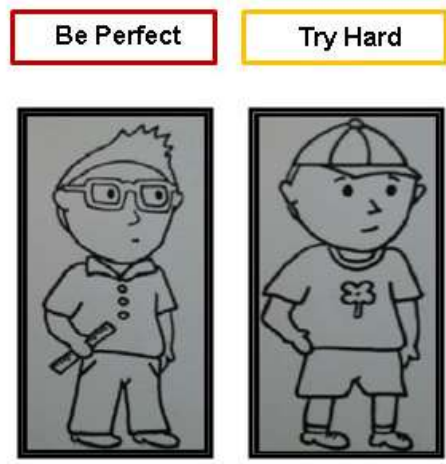

Mister Misurin

\section{Fortunello}

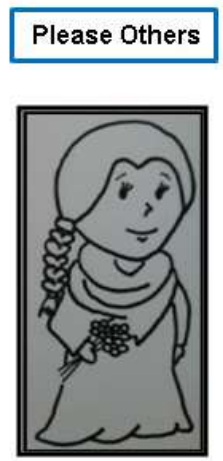

Occhidolci
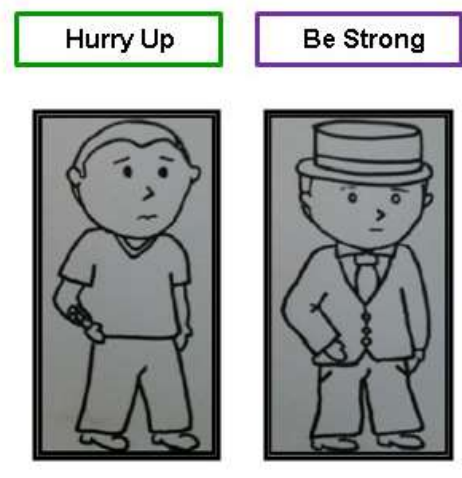

Tuttofare Nientefa

Mbé

Figure 5: The Characters 

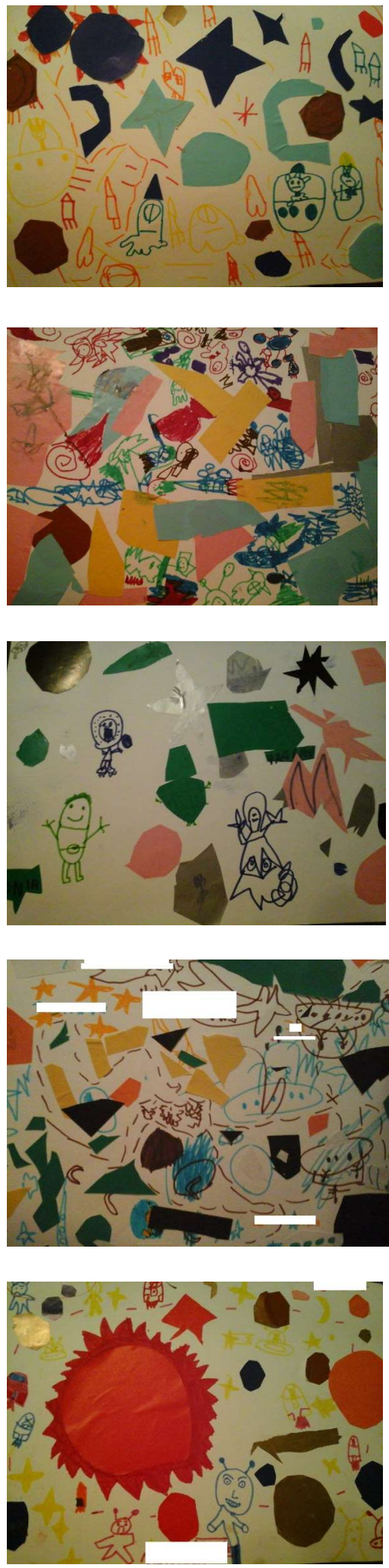

Figure 6: Intergallactic Maps
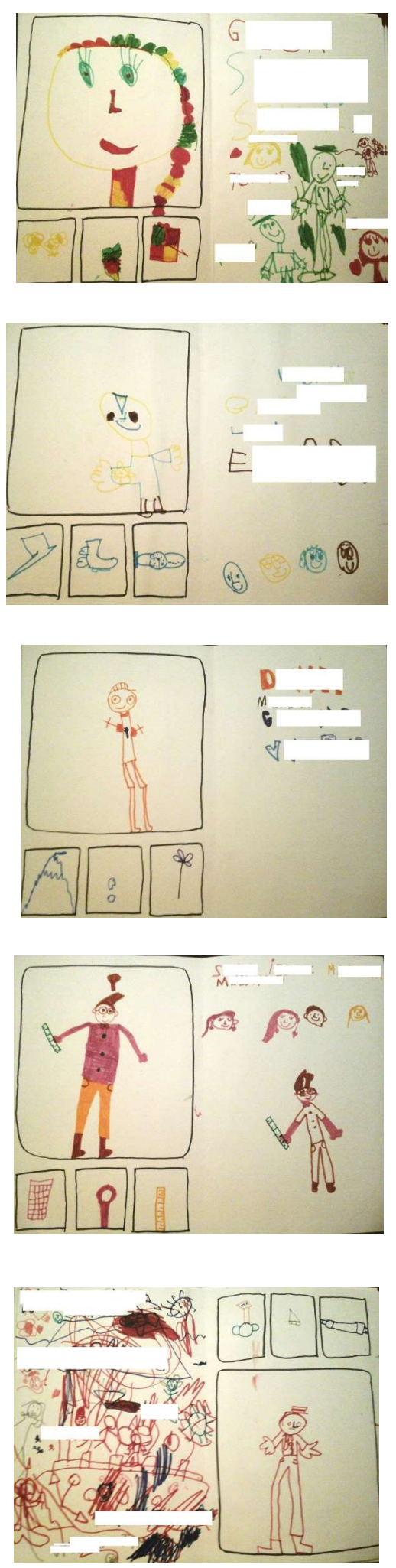

Figure 7: Passports 

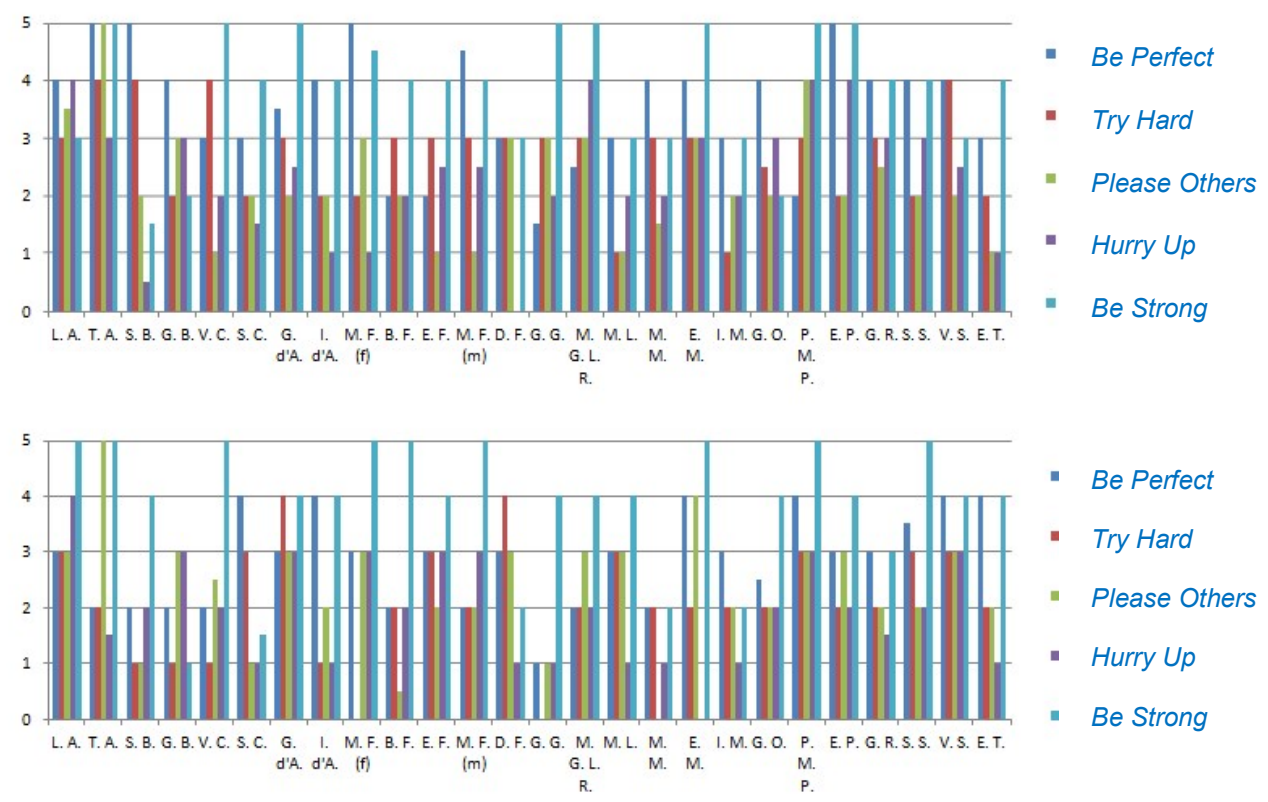

Figure 8: Changes in behavioural profiles
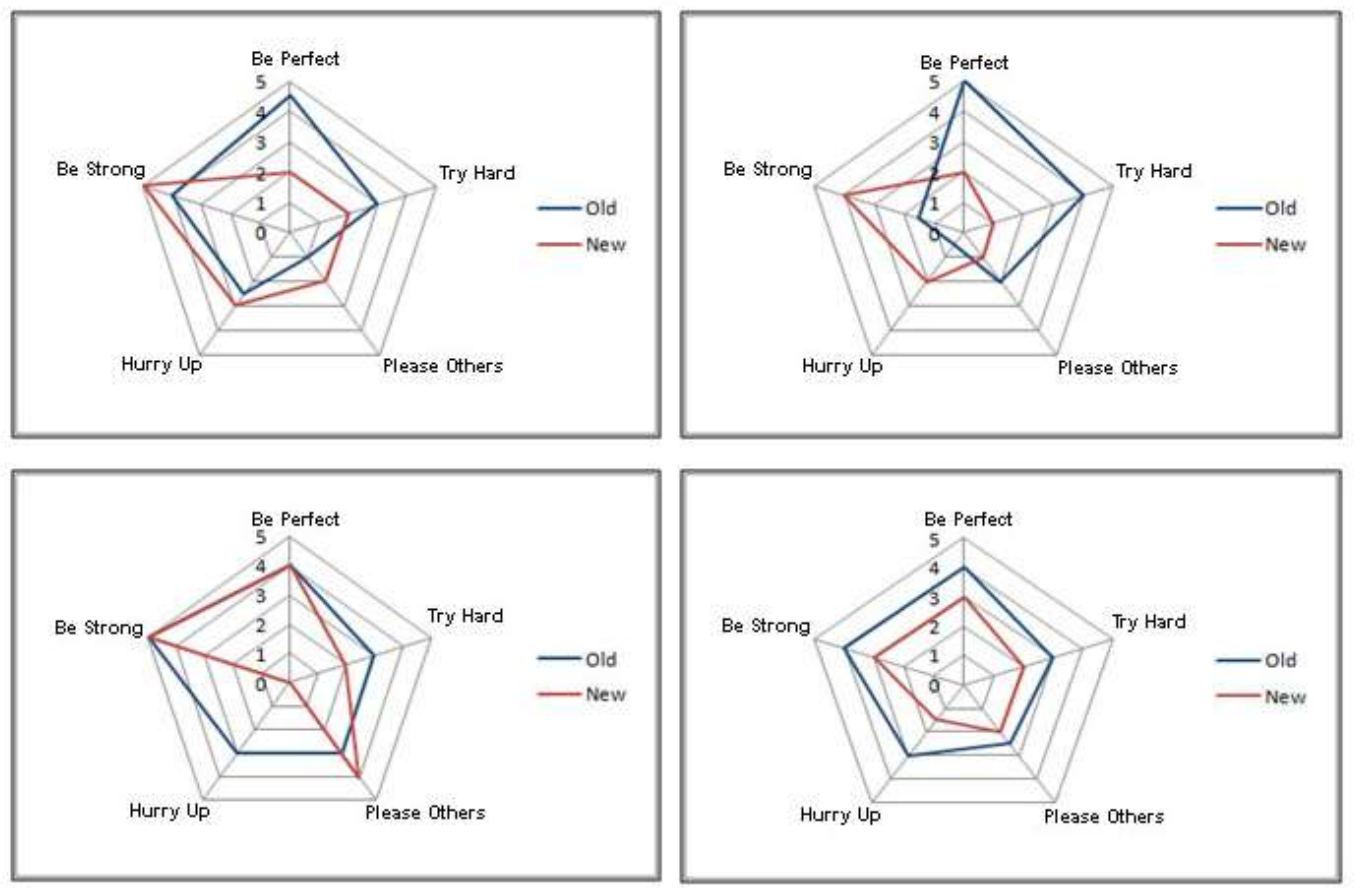

Figure 9: Examples of particular changes 


\section{Discussion}

These studies have been published to indicate how a range of research projects can be applied to research the links between TA and the education of young children.

There are of course several limitations:

- the studies were all completed within a particular locality of a particular country

- the questionnaires and instruments used were being developed within the research projects so there had been no prior validation

- the supervision of the researchers was conducted by authors whose work in several cases provided the basis for the design of new variations of questionnaires, with the obvious problem that they might not have been sufficiently neutral when considering the revised designs

- only an overview of each study is provided; a more complete reporting would require the inclusion of much more information and hence a separate paper for each study.

However, there is still enough information within the summary of results to indicate that attention to the overt teaching of TA concepts leads to the creation of a more positive teaching environment and children who have increased in self-awareness and autonomy.

\section{Conclusion}

Our hypothesis was that attention could be paid by teachers to affective variables just as they attend to metacognitive variables. Hence, our outcomes in the two studies have implications for the training of teaching as well as for children.

Those of us at the Scuola will continue to generate such studies and it is our hope that the publication of this material will stimulate others to undertake similar initiatives elsewhere so that we may begin to build up an international collection of such case studies.

In this way, we hope to demonstrate how useful it can be to include TA-based training within teacher education.
Cesare Fregola is a Provisional Teaching \& Supervising Transactional Analyst (Educational), Mathematics Didactics for Integration Professor in Degree Courses in Science of Primary School Teaching at University of Aquila and Lecturer in Mathematics and Psycho-pedagogy Didactic Masters Mathematics Art Science and Reality at Science of Teaching faculty University of Roma Tre. $\mathrm{He}$ can be contacted at fregola@uniroma3.it; cfregola@mathetica.it.

\section{References}

Alberici, A. (1999), Imparare sempre nella societa della conoscitva. Dall'educazione degli adulti all'apprendimento durante il corso della vita. Torino, Paravia.

Ballanti, G. (1979), Analisi e modificazione del comportamento insegnante, Teramo, Giunti \& Lisciani.

Berne, Eric (1964) Games People Play New York: Grove Press

Bloom, B.S. (1974), Stabilita e mutamento delle caratteristiche umane, Armando, Roma, (l'edizione italiana e a cura di Meschieri L.)

Boscolo, P. (1997), Psicologia dell'apprendimento scoloastico. Aspetti cognitive e motivazionali, Torino, UTET.

Bronfenbrenner, U. (1979), Ecologia dello sviluppo cognitive, Roma, Armando.

Chalvin, M.J. (1986), AT ed insegnamento scolastico, Roma, Paoline

Cornoldi, Cesare \& De Beni, Rossana (1991) Memory for discourse: Loci mnemonics and the oral presentation effect Applied Cognitive Psychology 5:1 511-518

Corsaro W (1985), Friendship and peer culture in the early years, N.J. Norwood, Ablex

De Landsheere, G. (1976), Storia della Pedagogia Sperimentale. Cento anni di ricerca educative nel mondo, Roma, Armando.

Fregola C, lozzelli A (2012) TA, relationship with one's own learning process and strategic studying International Journal of Transactional Analysis Research 4:1 67-79

Fregola, C. \& lozzelli, A. (2013), TA, Relationship with One's Own Learning Process and Strategic Studying in International Journal of Transactional Analysis Research 4:167-89 
Fregola, C. (1982), Matemarica e Mastery Interacting 10, Formazione Domani, Roma IAL CISL.

Fregola, C. (1989), Mastery Interacting e divulgazione Agricola, Quaderni A.F., Napoli, FORMEZ.

Fregola, C., (2010), Mathematical Calculation Procedures and Drivers in Action in the Learning Environment in International Journal of Transactional Analysis Research $1: 1$

Fregola, C \& Olmetti Peja, D (2007) Superare un esame: Transformare ansia, emotività e studio in risorse strategiche Napoli: Edises

Gagné, R.M. (1973), Le condizioni dell'apprendimento, Roma, Armando.

Hill, W.F. (2000), L'apprendimento. Interpretazioni psicologiche, Bologna, Zanichelli.
Kahler, Taibi (1975) Drivers: The Key to the Process of Scripts Transactional Analysis Journal 5:3 280-284

Lèvy, P. (1997), I/ virtuale, Milano, Raffaello Cortina.

Maragliano, R. (2007), Nuovo manual di didattica multimediale, Bari, Laterza.

Marrone, G., Eds. (2012), Maestre e Maestri d'Italia, Roma, Conoscenza.

Moiso, C. \& Novellino, M. (1982), Stati dell'lo. Roma, Astrolabio

Olmetti Peja, D. (1998), Teorie e tecniche dell'osservazione in classe, Firenze, Giunti.

Steiner, C. (1999), L'Alfabeto delle emozioni, Sperling e Kupfer Editori S.p.A., Milano. 